\title{
Un siglo y medio después. El estudio económico de la evolución humana
}

A century and a half later. The economic study of human evolution

\author{
ARCADI NAVARRO
}

Universitat Pompeu Fabra — (ICREA) — Institut de Biologia Evolutiva (UPF-CSIC)

arcadi.navarro@upf.edu (ESPAÑA)

Recibido: 01.032011

Aceptado: 19.01.2012

\section{RESUMEN}

Desde la publicación en 1859 de The Origin of Species y en 1871 de The descent of man, dos de las obras capitales de Darwin, el estudio científico de la evolución de las características específicas de los humanos ha sido el objeto de grandes esfuerzos provenientes de diversas áreas de la ciencia. Hoy en día, después de un siglo y medio de investigaciones se han acumulado resultados impresionantes sobre qué es aquello que, separándonos del resto de primates, «nos hace humanos» y sobre cómo puede haber evolucionado. En los últimos años una nueva área de investigación, liderada, sorprendentemente, por economistas, está empezando a hacer contribuciones importantes en el estudio de la hominización.

\section{PALABRAS CLAVE}

Evolución, Comportamiento humano, Asociación genética.

\section{SUMMARY}

Since the publication of The Origin of Species in 1859 and The Descent of Man in 1871, two of Darwin's major works, the scientific study of the evolution of the specific characteristics of humans has been the subject of great efforts from various areas of research. Today, after more than a Century, impressive re- 
sults have accumulated on what may «make us human», separating us from from other primates, and how it may have evolved. In recent years a new area of research led, surprisingly, by economists, is starting to make important contributions in the study of human evolution.

\section{KEY WORDS}

Evolution, Behavior, Genetic Association.

\section{INTRODUCCIÓN}

Hace 152 años que Charles Robert Darwin publicó The Origin of Species (Darwin, 1859). Desde entonces, el estudio de la evolución de las características específicas de los humanos ha sido el foco de grandes esfuerzos provenientes de muy diversas áreas de la actividad científica. Empezando por el mismo Charles Darwin, quien en 1871 publicó The Descent of Man and Selection in Relation to Sex, algunos de estos esfuerzos han resultado mejor orientados que otros y, de hecho, ha habido épocas en que las aproximaciones pretendidamente científicas a los rasgos específicos de los humanos han sido tan erróneas que ha costado años que el campo recuperara su prestigio. De todos modos, después de un siglo y medio de investigación se han acumulado resultados impresionantes sobre qué es lo que, separándonos del resto de primates, «nos hace humanos» y sobre cómo puede haber evolucionado.

Sólo a título de ejemplo, podemos mencionar que los paleontólogos han obtenido una filogenia muy completa de nuestra especie (Jobling et al. 2004); que los genéticos han podido secuenciar nuestro genoma y compararlo con el de otros organismos (e.g. Mikkelsen et al. 2005) incluyendo el de los Neandertales, que también han sido secuenciados (Green et al, 2010); que los neurocientíficos están empezando a entender los circuitos neuronales que siguen nuestros pensamientos (e.g. Fehr y Camerer, 2007) y que los economistas llevan a cabo detallados experimentos que nos permiten entender nuestras motivaciones más íntimas a la hora de resolver problemas o tomar decisiones (Camerer y Fehr 2004).

A pesar de la abundancia e indudable importancia de todos estos descubrimientos, su interpretación se ha demostrado llena de dificultades. Especialmente en lo que se refiere a un aspecto fundamental para entender nuestra evolución: la base genética de las características específicamente humanas. Estos graves problemas pueden ilustrarse con las largas discusiones, que ya duran décadas, sobre la heredabilidad de determinados caracteres. En genética, se usa el concepto técnico de heredabilidad para describir la proporción de la variación en un rasgo que se debe a los genes. Es decir, el componente genético de un carácter. Se habla, por ejemplo, de que la heredabilidad de la altura humana, que puede ser 
hasta de un 85\% (Manolio et al. 2009; Yang et al. 2010) o la del coeficiente intelectual (CI), que se estima entre el 50\% y el 70\% (Bouchard 2004). El problema con estas cifras es que son mal interpretadas con facilidad. Se suele pensar que quieren decir que la altura o el CI están determinados por los genes en un $85 \%$ o en un $50 \%$, pero eso no es cierto, sólo se quiere indicar que de toda la variación que observamos en, por ejemplo, la altura de las personas, un $85 \%$ es atribuible a variaciones genéticas mientras que sólo un $15 \%$ lo es a variaciones ambientales. Esta visión no implica ningún tipo de determinismo. Por ejemplo, el número de orejas con que contamos los humanos (normalmente dos) es determinado por los genes con absoluta precisión, pero la heredabilidad del número de orejas es casi $0 \%$, simplemente porque no hay variaciones genéticas en este carácter, sino sólo ambientales. Es decir, merced a un preciso programa genético, todos nacemos con dos orejas, pero en contadas ocasiones, hay accidentes que introducen variación en un rasgo determinado genéticamente. El caso de la altura y el CI es totalmente diferente, ya que la influencia del ambiente es omnipresente y continua.

Otra manera de ver este problema es el siguiente: si todos fuéramos clones, la heredabilidad de cualquier rasgo sería cero, independientemente de su grado de determinación genética, ya que no habría variantes genéticas contribuyendo a la diversidad de ningún aspecto de nuestros cuerpos o de nuestras mentes. Para los caracteres de alta heredabilidad, en ese mundo de clones todos seríamos iguales, para los caracteres de baja heredabilidad, seguiríamos observando la misma diversidad que observamos ahora. Dentro de unos momentos volveremos al concepto de heredabilidad pero lo que hay que entender por el momento es que, aunque la heredabilidad es una medida formal de la contribución de los genes a la variabilidad de cualquier característica de un organismo, y no una medida de determinación genética, resulta muy fácil confundirse. El concepto es tan contra-intuitivo que a lo largo de la historia ha sido pésimamente interpretado y peor usado infinidad de veces. Este es un problema que plaga los estudios sobre el origen evolutivo de los rasgos específicamente humanos: el terreno que explora es bastante desconocido y se usan términos y conceptos que hay que definir con mucha precisión, pero que siempre son fáciles de confundir ya que la tentación de simplificarlos y adaptarlos a nuestras intuiciones es grande.

Otra fuente de confusión en cuanto a la interpretación de los estudios genéticos surge de las noticias que aparecen regularmente en los medios de comunicación sobre «los genes de» $\mathrm{o}$ «los genes para» el alcoholismo, el lenguaje, la fidelidad, la memoria o las enfermedades más variadas. El hecho de que una variante de un cierto gen esté asociada a la variabilidad de un cierto carácter no quiere decir que el gen en cuestión sea importante en la determinación del carácter. Por ejemplo, el hecho de que determinadas variantes del gen FOXP2 estén ligadas a problemas en el habla de sus portadores (Enard et al. 2002), no quiere decir que FOXP2 sea «el gen del lenguaje». En primer lugar, porque muchos otros genes (decenas o quizás cientos) pueden estar involucrados en diversas funciones lingüísticas, y, en segundo lugar, porque la relación de FOXP2 con 
el lenguaje podría ser sólo indirecta o secundaria (Reimers-Kipping et al. 2010). Perder las llaves de ignición o arrancar el pedal del acelerador hace que un coche no se pueda poner en marcha ni conducir, pero ambas piezas son secundarias en relación al funcionamiento de un coche. Las ruedas o el émbolo sí son cruciales.

A pesar de todos estos problemas, y de muchos otros que sería demasiado largo explicar, durante los últimos diez años se han registrado continuos avances en nuestro conocimiento sobre la arquitectura genética de los caracteres complejos, especialmente de las enfermedades. Desde hace cinco años, por ejemplo, se dispone de la tecnología necesaria para el análisis en paralelo de un millón de marcadores genéticos repartidos por todo el genoma y hace apenas un año se ha publicado la primera fase del proyecto de los 1000 genomas (www.1000genomes.org) dentro del que se pretende obtener el genoma completo de más de 2500 individuos humanos y así disponer de un catálogo completo de variantes genéticas que puedan relacionarse con enfermedades tales como la diabetes, el cáncer, la esclerosis múltiple y muchísimas más. Pues bien: todas las herramientas desarrolladas para profundizar en rasgos humanos de interés clínico o socio-sanitario, están a nuestra disposición conocer mejor la arquitectura genética de los caracteres específicamente humanos.

Una frontera que durante los últimos tres años se ha movido con especial velocidad es la de la genoeconomía: el estudio de cómo la variación genética individual interacciona con nuestro ambiente social para explicar caracteres de tipo económico, todos ellos específicamente humanos, como nuestra percepción sobre la justicia de un intercambio de bienes por dinero « ¿Me ha salido barato o exageradamente caro?» o bien nuestra capacidad de pensamiento estratégico «¿Sabe Marta que yo sé que va a pedir un aumento de sueldo?». Curiosamente, nos acercamos a la evolución humana, a la genética de la hominización, por un camino distinto del que siempre habíamos pensado: la mayor parte de novedades no provienen del estudio de las capacidades clásicamente consideradas «superiores», como la racionalidad, el lenguaje, o la capacidad humana para la abstracción o la moral, sino que provienen de un ámbito tradicionalmente considerado prosaico: las relaciones económicas. En lo que sigue, revisaré algunas de las líneas de investigación más prometedoras dentro de este nuevo campo, pero primero necesitamos entender porque la genoeconomía es posible hoy y cuáles son los avances que la han convertido en una realidad.

\section{DOS CAMBIOS DE PARADIGMA}

Durante los cinco últimos años hemos vivido dos cambios fundamentales en el foco de la investigación biomédica. Ambos cambios son de gran importancia para el estudio de los rasgos propios de los humanos. El primero de estos cambios es el advenimiento de la genómica personal. Parece que hayan pasado décadas, pero fue apenas en 2001 cuando se hizo público «EL» Genoma Humano. Hoy en día sabemos que no existe tal cosa como un único genoma humano (Pen- 
nisi 2007). Las diferencias genéticas entre cualquier par de personas que elegimos comparar son enormes (siempre y cuando no sean gemelos idénticos, claro). Dentro de los tres mil millones de nucleótidos que configuran nuestros genomas, dos seres humanos cualquiera se diferencian en, aproximadamente, un $0.1 \%$ y un $1 \%$. Puede no parecer mucho, pero se traduce en unos cifra de entre 3 millones y 30 millones de nucleótidos de diferencia (The 1000 Genomes Project Consortium 2010; Sudmatan et al. 2010). Estas cifras resultan todavía más impresionantes si se mira más allá de dos personas y se considera cuántas diferencias puede haber entre grupos más grandes de individuos, como toda la especie humana. Y aún más, si cabe, cuando uno se da cuenta de que las diferencias genéticas entre humanos no incluyen sólo mutaciones puntuales, que serían análogas a tener, en una biblioteca, dos ediciones diferentes del mismo libro. Algunas de las diferencias, las llamadas variaciones en número de copia, son de tal magnitud que son análogas a diferentes colecciones de libros. Son diferencias de un tamaño tan grande que a veces incluyen genes completos. Genes que pueden estar presentes más de una vez en una persona, mientras que otras personas están totalmente carentes.

En estas diferencias está la base de nuestra individualidad genética: codifican nuestro grupo sanguíneo, el color de nuestra piel, el metabolismo diferencial de distintas personas o su susceptibilidad diferencial a determinadas enfermedades. No es sorprendente que cada vez entendamos mejor las diferencias entre nuestros genomas, ya que este conocimiento es un paso necesario para alcanzar uno de los hitos más importantes del siglo XXI: la medicina personalizada. La gran cantidad de recursos dedicados a la investigación en este campo son una gran ventaja para el estudio de la evolución humana, ya que dar cuenta de la diversidad de nuestros genomas es fundamental para hacer avanzar el estudio de las bases genéticas de cualquier carácter, incluidos aquellos que no tienen interés clínico, pero sí evolutivo.

El segundo cambio de perspectiva va más allá de la investigación con propósitos clínicos, pero en último término también se deriva de ésta. Se trata de la plena aceptación de la importancia de la diversidad normal en biología y en cualquier aspecto del estudio de los humanos. Dejando de lado la clasificación de la diversidad humana entre «normal» y «patológica», hoy en día los científicos entienden que la patología suele encontrarse en los extremos de las distribuciones de conjuntos de variables enormemente complejos. Los investigadores se han dado cuenta que no pueden entender la fisiología o la bioquímica de la enfermedad sin una perspectiva global del continuo al que pertenecen los estados patológicos. Así pues, la exploración detallada de las diferencias individuales a cualquier nivel, desde las moléculas hasta el comportamiento, ha comenzado. Y una vez más, los resultados de esta empresa serán beneficiosos para nuestra comprensión de la evolución de los rasgos que, a lo largo de la evolución, nos han hecho humanos.

En resumen, ambos cambios han hecho posible la genoeconomía. No sólo porque el campo pueda beneficiarse de las herramientas y las técnicas creadas 
para estudiar la arquitectura genética de las enfermedades, sino porque el ambiente intelectual se ha vuelto propicio. Nunca como ahora se había comprendido la importancia de la diversidad individual. Y la diversidad es la materia prima de la Evolución.

\section{ESTUDIOS CON GEMELOS}

La genoeconomía comenzó mediados del siglo XX, cuando, en los estudios clásicos de gemelos, se empezaron a considerar algunos caracteres (llamados «fenotipos» en términos técnicos) relacionados, directa o indirectamente, con la economía (Jobling et al. 2004). Estos estudios revelaron contribuciones genéticas relativamente importantes a fenotipos como los ingresos, el coeficiente intelectual, el nivel educativo, la tendencia a afrontar riesgos, el comportamiento emprendedor y muchas otras características socio-económicas (Martin et al. 1997; Boonsma et al. 2002; Bouchard et al. 2003; Bouchard 2004). Los estudios clásicos con grupos de gemelos estiman la heredabilidad (recordemos, la proporción de la diversidad de un carácter que se puede atribuir a la diversidad genética) comparando gemelos idénticos (que son genéticamente iguales, clones que comparten el $100 \%$ de los genes) con gemelos fraternales (que son como hermanos normales y comparten el $50 \%$ de los genes). Si, para un fenotipo concreto los gemelos idénticos se comportan de manera tan similar como lo hacen los gemelos fraternales, la interpretación es que el componente genético, es decir, la heredabilidad del fenotipo en cuestión debe ser baja y que, por tanto, la contribución de la diversidad genética a la diversidad observable para ese fenotipo debe ser baja. Si, por el contrario, los gemelos idénticos son mucho más similares entre ellos que los gemelos fraternales, entonces, la proporción de la variabilidad del carácter que explican las variantes genéticas debe ser alta, ya que lo único que los gemelos idénticos tienen más en común entre ellos que los gemelos fraternales son, precisamente, variantes genéticas.

El aspecto clave de estos estudios es hasta qué punto sus conclusiones son generalizables. ¿Cuán representativos de la variabilidad humana general son los gemelos estudiados? ¿Los gemelos idénticos, son tratados de manera más similar (porque es fácil, por ejemplo, que se les tome el uno por el otro)? Los estudios más modernos han logrado superar estas dificultades y los análisis rigurosos que abordan fenotipos muy diversos con grupos gemelos se suceden desde hace tiempo. De hecho, los estudios con gemelos constituyen, en muchos casos, la única pieza de evidencia experimental de que una enfermedad compleja tiene un componente hereditario y que, por tanto, merece la pena estudiar su arquitectura genética. Cuando más baja es la heredabilidad de una enfermedad, más magras son las posibilidades de encontrar algún factor genético que la esté influenciando.

Una vez más, hay que insistir en la prudencia que requiere el uso del concepto de heredabilidad. Si la investigación científica revela que un rasgo concreto 
tiene una heredabilidad de un 60\%, no significa que el $60 \%$ de los casos de este fenotipo estén «causados por los genes». Como hemos visto hace unos párrafos, lo que esa cifra significa es que si todos fuéramos clones pero el rango de ambientes en que nos movemos se mantuviera, sólo veríamos el $40 \%$ de la diversidad fenotípica que vemos ahora. Puesto en términos simétricos, si todos nos criáramos en exactamente en mismo ambiente, veríamos aproximadamente un 60\% de la variabilidad que ahora vemos, puesto que las diferencias genéticas seguirían manifestándose. También es importante darse cuenta de que el hecho de que un rasgo tenga una heredabilidad del $60 \%$ no quiere decir algo tan simple como que un solo gen explique el $60 \%$ de la variabilidad fenotípica que observamos. La mayor parte de los rasgos humanos, especialmente los que nos hace únicos entre los primates, son caracteres poligénicos, codificados por varios genes, y las complejas interacciones que puede haber entre estos genes o entre los genes y el ambiente simplemente se desconocen. Este es, por cierto, otro punto importante: en la mayoría de ocasiones los genes y el ambiente no actúan independientemente. Los individuos, por ejemplo, influyen, seleccionan, o incluso construyen, sometidos a la influencia de sus genes, el ambiente en que han de vivir y, por tanto, el entorno en que estos genes serán expresados.

A pesar de todos los potenciales problemas mencionados, es sorprendente ver como las medidas de la heredabilidad de los caracteres socio-económicos son de magnitudes similares que las de fenotipos físicos como determinadas enfermedades (Bouchard et al. 2003; Bouchard 2004). Este hecho sugiere que el comportamiento económico humano puede estar sometido a una influencia genética mayor que el que habíamos pensado hasta ahora.

\section{ASOCIACIONES ENTRE VARIANTES GENÉTICAS Y FENOTÍPICAS}

Una vez está claro que un fenotipo concreto tiene uno componente genético, el siguiente paso es intentar diseccionarlo con la máxima precisión. Los investigadores se hacen preguntas tales como ¿Cuántos factores genéticos influyen el carácter bajo estudio? ¿Qué efectos tienen? ¿En qué lugares de nuestro genoma los podemos encontrar? ¿De qué tipo son? ¿Se trata de variantes genéticas puntuales que cambian la manera en que se pliega una proteína, o bien actúan a través de modificaciones en el nivel de expresión de determinados genes? ¿ $\mathrm{O}$ son quizás variantes estructurales?

En epidemiología clásica, la concurrencia en una población, con más frecuencia de lo esperado por el azar, de un fenotipo (el carácter bajo estudio) y una variante genética concreta (por ejemplo, una versión específica de un gen, lo que se denomina, un alelo) recibe el nombre de «asociación genética». Las asociaciones que más se conocen son las que se han podido detectar entre fenotipos relativamente sencillos, como padecer o no tener una enfermedad, y variantes genéticas también simples, como los Polimorfismos de un Solo Nucleótido, en 
inglés SNPs, que son cambios en una sola posición de la cadena del ADN (Cardon y Bell, 2001; WTCCC, 2007).

Hay que notar que, como siempre ocurre en estadística, asociación no significa causalidad. El escenario más probable es que la variante genética, el alelo, que ha sido asociado a la presencia de un fenotipo concreto no tenga nada que ver a nivel causal. Lo que suele suceder es que la variante genética en cuestión (denominada marcador genético) está asociada, a su vez, con una otra variante o grupo de variantes (a las que se llama variantes causales) que son las que realmente contribuyen al fenotipo de interés. Éste es el escenario más probable ya que, de entre los millones de variantes genéticas que diferencian a los humanos, sólo una fracción muy pequeña tienen consecuencias (The 1000 Genomes Project Consortium, 2010). La mayor parte de variantes genéticas no tienen ningún efecto funcional sobre fenotipo alguno, pero como pueden estar asociadas con variantes causales, se las puede usar como marcadores genéticos.

El diseño experimental más común de la epidemiología clásica es el estudio caso-control (Cardon y Bell, 2003). Los estudios caso-control usan sujetos que tienen un cierto fenotipo (llamados «casos», que normalmente padecen una enfermedad, pero que también pueden presentar otras condiciones) y tratan de determinar si hay características de estos individuos que los diferencian de aquellos que no presentan el fenotipo (llamados «controles»). La epidemiología clásica ha servido para demostrar que el hábito de fumar es más frecuente en pacientes con cáncer de pulmón. Ahora bien, las cadenas causales son harina de otro costal. Sin más datos, o sin la investigación adecuada en el laboratorio, la conclusión del estudio que acabamos de mencionar podría ser que el cáncer de pulmón produce un deseo irrefrenable de fumar.

En la epidemiología genética, los estudios caso-control, comparan las frecuencias de muchos marcadores genéticos entre casos y controles. Los marcadores pueden ser cualquier variante genética de las que hemos visto hasta ahora. Los casos serán, como antes, pacientes que presenten la enfermedad o el carácter bajo estudio. El grupo de controles estará formado por individuos de los que se sabe que no presentan la enfermedad o bien que han sido seleccionados al azar de entre la población general. Una diferencia estadísticamente significativa en la frecuencia de una variante genética entre los dos grupos indica una «asociación» de la presencia de determinado alelo con un riesgo incrementado de padecer la enfermedad o de presentar el carácter.

Como es lógico, la tarea de seleccionar, de entre los millones disponibles, los marcadores genéticos que han de utilizarse es una tarea de gran complejidad. De todos modos los desarrollos tecnológicos de los últimos años la han facilitado en gran medida. Hoy en día, no sólo podemos elegir de un catálogo de millones de marcadores genéticos pre-definidos, sino que las plataformas de genotipado de alto rendimiento basadas en «microarrays» de alta densidad han disminuido en órdenes de magnitud el coste de determinar de qué marcadores genéticos es portador cada individuo. Además, las tecnologías de ultrasecuenciación están cerca de ser capaces de leer, ya no un conjunto más o menos grande de marcadores, 
sino el genoma completo de un individuo a precios completamente irrisorios (ver «The Sequence Explosion» en el número del 1 de Abril de 2010 de la revista $\mathrm{Na}$ ture).

En términos generales, hay dos tipos de aproximación a los estudios de asociación: estudios dirigidos o estudios de genoma completo. Los estudios dirigidos se centran en una lista de genes «candidatos» o de regiones genómicas de interés. Estas listas se compilan a partir de los conocimientos actuales sobre una enfermedad o un carácter concretos. Por ejemplo, si se estudian las bases genéticas de la depresión, tiene todo el sentido seleccionar marcadores genéticos localizados en los genes de la ruta de la serotonina. El número de marcadores en estos estudios varía desde apenas unos pocos (incluso se puede genotipar un solo marcador) hasta varios miles. En las dos últimas décadas se han publicado más de 80.000 de estos estudios cuyos resultados se sistematizan en bases de datos de acceso público (http://geneticassociationdb.nih.gov/).

El enfoque de los estudios de genoma completo es radicalmente distinto. Estos estudios examinan marcadores genéticos, incluso millones de ellos, distribuidos por todo el genoma humano. No parten de ninguna hipótesis previa sobre cuáles pueden ser las regiones del genoma o los genes con más o menos influencia sobre el carácter que estudian, sino que están diseñados para tratar de detectar cualquier posible asociación. En los últimos cinco años se viene publicando una cantidad creciente de estudios de asociación de genoma completo. La mayoría de estos estudios, el número actual de los cuales ya supera los 1400, son también accesibles en bases de datos públicas (ver http://www.genome.gov/ GWAStudies).

Dos décadas de estudios de asociación han producido tanto éxitos como frustraciones. La principal causa de fracasos han sido los muchos ejemplos de putativas asociaciones que, tras varios intentos fallidos de replicación, han sido reconocidos como falsos positivos (Ioannides, 2001; Ioannides et al. 2007). En cualquier caso, un número creciente de asociaciones han sido verificadas mediante diversos métodos en experimentos independientes (ver http://www.genome.gov/GWAStudies). Hoy en día, los mecanismos de muchas enfermedades se conocen suficientemente bien como para que una panoplia cada vez más completa de medicamentos se esté desarrollando y poniendo al servicio de la salud pública. Poner este tipo de herramientas tecnológicas al servicio de la investigación en biología evolutiva, especialmente en cuanto a la hominización, era sólo una cuestión de tiempo.

\section{LA CORRECTA MEDIDA DEL HOMBRE. ¿FENOTIPOS ECONÓMICOS?}

El comportamiento humano puede medirse en un sinfín de maneras, así que escoger las adecuadas es un asunto importante. Si lo que queremos es estudiar genoeconomía, ¿qué fenotipos debemos medir? A través de la historia, los 
científicos sociales han usado varias medidas indirectas del comportamiento social. Fenotipos como la trayectoria profesional, los ingresos, el nivel de deuda o la cantidad de capital acumulado nos proporcionan medidas «distales» de fenotipos económicos y han sido de uso general en muchos estudios (Camerer 2003; Camerer y Fehr 2003). Las medidas directas del comportamiento económico han sido menos utilizadas, pero cada vez se presta más atención a variables como la aversión al riesgo, la paciencia o el grado de confianza en los demás, que no sólo son variables más simples que las medidas indirectas, sino que son fenotipos más «proximales» al proceso de toma de decisiones. Esa aparente proximidad a la biología sugiere que es razonable esperar que su arquitectura genética sea más simple que la de un fenotipo tan complejo como los ingresos anuales de una persona. Independientemente de cuán "proximales o distales» sean determinados fenotipos, todas estas medidas tienen algo en común: se obtienen a través de cuestionarios de auto-evaluación que los sujetos experimentales contestan. Muchas de las respuestas de estos cuestionarios, que reflejan lo que el individuo piensa de sí mismo o lo que desea que otros piensen de él, no pueden ser verificadas, con el consiguiente problema de credibilidad de los resultados de estos estudios.

En las últimas décadas ha surgido, desde el campo de la economía experimental, una aproximación radicalmente diferente a las medidas del comportamiento humano. La economía experimental es una rama de las ciencias económicas que tiene las mismas características que cualquier otra ciencia experimental: aspira a ganar conocimiento sobre el comportamiento de los humanos en condiciones controladas, con el objetivo o bien de evaluar teorías o asunciones sobre el funcionamiento de nuestras mentes, o bien de obtener datos que puedan usarse para desarrollar nuevas hipótesis (Camerer 2003). Los economistas experimentales usan un amplio abanico de tipos de estudio, diseñados para llevar a cabo tanto en el laboratorio como en campo. Estos experimentos (llamados «juegos «) tienen varias ventajas sobre los cuestionarios de autoevaluación o de evaluación por parte de terceros (Camerer, 2003; Ebstein, 2006), ya que son más realistas. Motivan a los sujetos ofreciéndoles recompensan monetarias, por lo que la tendencia a fingir disminuye, ya que las personas que participan en el experimento han de responder con hechos (ganando o perdiendo dinero) y no sólo con palabras.

Otra ventaja de los estudios de economía experimental es que permiten a los investigadores obtener medidas muy simples de las diferentes actitudes o estrategias que pueden adoptar los sujetos en el contexto de un juego. Por ejemplo, hay juegos diseñados para estudiar las preferencias sociales que miden la actitud que los sujetos experimentales tienen para con los intereses y el bienestar de los demás. Estos juegos, como el juego del ultimátum, el juego del dictador o el juego de los bienes públicos permiten medir el comportamiento de los sujetos en términos numéricos sencillos que se traducen en el grado de altruismo o de confianza en los demás de un individuo, o bien en sus preferencias por la equidad o la reciprocidad. 
Un ejemplo canónico es el del juego del ultimátum. En la versión original de este juego dos jugadores interaccionan una única vez y de manera anónima. A un jugador se le asigna el rol de «proponente» y al otro el de «decididor». El proponente debe hacer una oferta sobre cómo repartirse una suma de dinero con el decididor. El decididor puede, si quiere, aceptar la oferta o bien, si así lo desea, rechazarla. Si el decididor rechaza la oferta, ambos pierden el dinero, si, en cambio, la acepta, el dinero se reparte según la oferta del proponente. En este tipo de escenario, si los humanos fuéramos «maximizadores racionales de nuestro propio beneficio», según habían defendido algunos pensadores clásicos, el resultado debería ser claro. El proponente debería hacer una oferta de mínimos, dando poco dinero al Decididor, y el Decididor debería aceptar cualquier oferta que no fuera de cero (por aquello de que más vale pájaro en mano que ciento volando). Sorprendentemente, este tipo de comportamiento egoísta y racional casi nunca se da. El juego del ultimátum se ha jugado miles de veces en todo el Planeta y se ha podido observar que, en su mayoría, las personas están dispuestas a sacrificar sus ganancias, rechazando ofertas que pueden considerarse «injustas» $\mathrm{o}$ «desequilibradas». En este sentido, no es extraño que haya decididores que rechacen ofertas que no sean de, al menos, el $20 \%$ o el $30 \%$ del dinero. Este comportamiento se ha descrito como «castigo altruista», porque castiga a individuos anónimos a cambio de un coste por la persona que impone el castigo, el beneficiario es la sociedad y el beneficio por castigador es sólo indirecto El umbral a partir del que se rechazan las ofertas puede interpretarse como una medida numérica simple de la tendencia a la equidad y a la cooperación o bien de la aversión a ofertas poco generosas.

Aunque las medidas obtenidas en estos experimentos sean interpretables, lo que no puede negarse es su simplicidad ni tampoco el hecho que son medidas controladas, cuantitativas y repetibles, ya que los experimentos se pueden realizar en cualquier laboratorio de todo el mundo. En este sentido, pueden ser consideradas como medidas atómicas del comportamiento económico humano. Como tales, se han convertido en el paradigma experimental central de la genoeconomía. Del mismo modo que los investigadores en neuroeconomía estudian neuroimágenes del cerebro de los sujetos mientras éstos realizan determinadas tareas (que pueden ser «juegos» como el del ultimátum), los investigadores en genoeconomía estudian los genotipos de los individuos experimentales intentando buscar marcadores genéticos asociados a determinadas actitudes o estrategias.

\section{UN ESTUDIO GENOECONÓMICO CON GEMELOS}

Uno de los primeros estudios modernos de genoeconomía fue publicado en 2007 por Magnus Jóhannesson y sus colaboradores (Wallace et al. 2007), del Massachussets Insitute of Technology (MIT). Este estudio constituye el primer intento de medir la heredabilidad de los resultados de un juego económico. En 
concreto, los autores usan un diseño experimental clásico con gemelos para medir la heredabilidad de la estrategia de los decididores en el juego del ultimátum. Sus resultados son sorprendentes: la heredabilidad del comportamiento de los decididores, medido como el umbral de rechazo de una oferta, es de un $42 \%$. Es decir, que las diferencias genéticas entre individuos ayudan a explicar el $42 \%$ de la diversidad observada en el nivel de la oferta que están dispuestos a rechazar los decididores. De todos modos, antes de entusiasmarse y hacer afirmaciones contundentes, hay que tener en cuenta todas las dificultades que hemos mencionado hasta ahora, y quizá algunas más. En cualquier caso, los resultados son los que son y diversos grupos de investigación han publicado desde entonces nuevos estudios con grupos más grandes de gemelos y con diferentes baterías de juegos económicos. Es importante añadir que el mismo grupo ha publicado medidas de heredabilidad de otros juegos y los resultados son bastante más modestos (Cesarini et al. 2008).

Desde el punto de vista evolutivo, el interés del estudio de MIT va mucho más allá de la demostración de que la influencia de los factores genéticos en el juego del ultimátum es grande. En primer lugar, este estudio ayuda a contextualizar décadas de investigación en genética del comportamiento y neurociencia. Por ejemplo, los niveles en sangre de determinadas hormonas, como la testosterona o la oxitocina, han sido correlacionados con el comportamiento de los participantes en juegos económicos (Kosfeld et al. 2005; aan het Rot et al. 2006). Así pues, tiene sentido plantear la hipótesis que los individuos con diferentes niveles basales de ciertas hormonas (niveles que, ciertamente, están bajo la influencia de los genes) pueden tener tendencia a mostrar diferentes comportamientos en determinados experimentos. Además, este estudio es consistente con los estudios de heredabilidad mencionados más arriba, que detectaron considerables efectos genéticos en una larga lista de variables socio-económicas, como la religiosidad o las preferencias políticas (Bouchard 2004).

En segundo lugar, este estudio tiene importantes implicaciones evolutivas. Se sabe poco sobre la evolución de rasgos como el sentido de equidad o, de hecho, sobre cualquiera de los fenotipos que hemos visto hasta ahora. Algunos autores argumentan que el castigo altruista refleja una tendencia universal que fue adaptativa por nuestros ancestros para mantener la cooperación entre individuos no emparentados. Otros basan sus explicaciones en modelos de reciprocidad indirecta basados en la gestión de la reputación. Una medida de heredabilidad no puede solucionar este tipo de dudas, pero ciertamente sirve para demostrar algo fundamental para que sea posible la evolución por selección natural: que los fenotipos seleccionados sean heredables. En otras palabras, para que un carácter favorable aumente de frecuencia en la población por acción de la selección natural, es necesario que haya variantes genéticas que contribuyan al carácter. Si toda la variación de un fenotipo es ambiental, la selección darwinista no puede actuar. Es muy interesante notar que hay heredabilidad, es decir, un componente genético, en las estrategias de rechazo del juego del ultimátum. Inmediatamente vienen a la cabeza preguntas fascinantes. ¿Si aún hay diversidad genética,

EMPIRIA. Revista de Metodología de Ciencias Sociales. N. ${ }^{\circ}$ 23, enero-junio, 2012, pp. 83-99. ISSN: $1139-5737$ 
quiere esto decir que no hay una estrategia óptima? ¿O quiere decir que, según las circunstancias, hay varias estrategias que son favorecidas por la selección natural?

Finalmente, el trabajo de Jóhannesson y sus colaboradores apunta a la interesante posibilidad de que una de las razones que, a lo largo de la historia, han hecho tan difícil de entender y modelar formalmente la diversidad de comportamientos humanos es que estos comportamientos pueden tener un componente genético importante.

\section{ESTUDIOS DE ASOCIACIÓN EN GENOECONOMÍA}

En marzo de 2008, Richard Ebstein y sus colaboradores, de la Universidad de Haifa, publicaron los resultados del primero de muchos estudios diseñados para testar la asociación de una o más variante genética con el comportamiento de los jugadores en experimentes económicos (Knafo et al. 2008). Para su estudio, el grupo de Ebstein se centró en el juego del dictador. Este juego es similar al juego del ultimátum, pero uno de los jugadores (el «dictador») es el que decide como distribuir el dinero. El otro jugador (el «receptor») se limita a un papel totalmente pasivo, en que sólo puede aceptar lo que le da su anónimo compañero. Dado que el receptor no tiene ningún poder y el dictador no está sometido a ningún tipo de influencia, la cantidad dinero que el dictador concede al receptor suele interpretarse como una medida de altruismo en estado puro. Dados los precedentes, los lectores no se sorprenderán de saber que el comportamiento de los dictadores normalmente se desvía de la maximización racional (que incitaría a quedarse con todo el dinero). Los dictadores habitualmente regalan una buena cantidad de dinero a los receptores. Aproximadamente un 80\% de los individuos comparten su dinero y, en el $20 \%$ de los casos, se reparten mitad y mitad (Camerer, 2003).

En el estudio de Ebstein se examinó una sola variante genética: un polimorfismo del gen del Receptor de la Arginina Vasopresina la (AVPR1a). El gen AVPR1a presenta, entre otras variantes, un elemento genético que tiene dos formas (el alelo «largo» y el alelo «corto»). Estas dos variantes han sido previamente asociadas con comportamientos sociales, especialmente con el autismo (Yirmiya et al. 2006). Además, el gen AVPR1a ha sido relacionado con el comportamiento sexual de una especie de roedores de campo (Lim et al. 2004; Hammock et al. 2005; Hammock y Young 2005, 2006; Young y Hammock, 2007). Ambas líneas de evidencia inspiraron el estudio de los investigadores de la Universidad de Haifa.

Sus resultados fueron claros: los individuos con versiones cortas del gen AVPR1a hacen ofertas significativamente menos generosas en el juego del dictador. Este hallazgo era coincidente con los niveles de altruismo que estos mismos individuos decían tener en un cuestionario de auto-evaluación. Como es habitual en los estudios de asociación, se investigaron los correlatos funcionales de 
la variante estudiada (es decir, las potenciales variantes causales que el marcador genético podía haber detectado). Un análisis post-mortem de tejido cerebral demostró que la variante larga del estaba ligada a una mayor expresión del gen AVPR1a en el hipocampo. Los problemas de los estudios de asociación que hemos visto en párrafos anteriores, hacen aconsejable tomarse con cuidado esta información. Podría ser perfectamente un falso positivo y debe ser confirmado por estudios independientes. De todos modos, estos estudios ya están en marcha y no tardaremos mucho en conocer los resultados.

Naturalmente, la variante que acabamos de mencionar no es la única que se ha asociado con comportamientos económicos y en los últimos años una auténtica avalancha de artículos, hechos con mayor o menor rigor, está poblando la literatura. Además, muchos grupos están llevando a cabo sus propios proyectos de investigación. Un ejemplo destacado es el del Estudio de Susceptibilidad Ene / Ambiente / Edad de Reykjavik (Ages-RS, ver Harris et al. 2007). Dentro de este estudio, se están midiendo varios fenotipos económicos distales en una muestra de más de 2000 individuos. En paralelo, un panel de genes previamente relacionado con fenotipos cognitivos y neurales ha sido genotipado en estos individuos mediante los marcadores genéticos adecuados. Y esta no es la única aproximación al problema: otros investigadores estudian juegos económicos, y aún otros realizan estudios de genoma completo. Está claro que, en los años venideros, podremos disfrutar de un cuerpo creciente de literatura que nos proporcionará datos valiosísimos sobre asociaciones de variantes genéticas con fenotipos económicos y que nos permitirán entender un poco mejor cómo estas características de nuestra especie pueden haber evolucionado.

\section{CONCLUSIÓN. EL PROGRAMA DE INVESTIGACIÓN DE LA GENOECONOMÍA EVOLUTIVA}

El objetivo central de la genoeconomía consiste en averiguar cómo las diferencias genéticas individuales pueden influenciar, a través de su interacción con el ambiente, el comportamiento económico humano. A lo largo de este artículo hemos visto que ninguno de los términos de la frase que encabeza este párrafo está libre de problemas. Sin embargo, ser consciente de estas dificultades no equivale a ser pesimista. Al contrario, cada término puede ser una palabra-clave para un área de investigación extremadamente atractiva. ¿Cómo podemos medir las influencias genéticas? ¿Cómo estimar las interacciones con el ambiente? ¿Cómo definir los fenotipos adecuados? ¿Cómo traducir asociaciones genéticas en cadenas causales que nos proporcionen auténticas explicaciones? Si se tiene éxito, aunque sólo sea parcial, al resolver estas cuestiones, los investigadores que trabajen en el área estarán haciendo algo que raramente es posible: están estableciendo los cimientos de una nueva ciencia. Pero ¿qué tipo de progreso podemos esperar? ¿Y a qué retos y dificultades vamos a enfrentarnos?

Las contribuciones de la genoeconomía pueden ser muchas. Especialmente

EMPIRIA. Revista de Metodología de Ciencias Sociales. N. ${ }^{\circ}$ 23, enero-junio, 2012, pp. 83-99. ISSN: $1139-5737$ 
en cuanto al estudio de la evolución humana. El primer tipo de descubrimientos que podríamos esperar es la identificación de las causas, tanto genéticas como ambientales (¡o ambas a la vez!) de los comportamientos económicos. Identificar cadenas causales es crucial, ya que puede ayudar a entender similitudes y diferencias entre individuos o grupos. En segundo lugar, describir la arquitectura genética de los fenotipos económicos puede ayudar a construir mejores modelos y teorías sobre cómo el comportamiento humano configura nuestra sociedad. En tercer lugar, el descubrimiento de los factores genéticos bajo fenotipos socioeconómicos nos proporcionará información fundamental para entender la historia evolutiva de este tipo de fenotipos de tanta importancia en el proceso de hominización. El último punto será especialmente fructífero si las variantes genéticas humanas pueden compararse con las de otras especies de primates, cuyos genomas completos están ya disponibles, como los chimpancés, los orangutanes o los neandertales. Podremos hacernos preguntas como ¿Qué genes han cambiado? ¿Podemos inferir cuando se produjo ese cambio? ¿Se observa la huella molecular de la fijación de nuevas variantes genéticas por selección natural? En este sentido, es muy prometedor que determinados juegos, como el del ultimátum, se hayan adaptado para ser jugados con chimpancés (Jensen et al. 2007a, 2007b).A pesar de todos los potenciales problemas, la genoeconomía, especialmente en su vertiente evolutiva, está llamada a proporcionarnos respuestas a algunas de las preguntas que Darwin se hizo hace más de 150 años. Será un campo multidisciplinar muy emocionante, $\mathrm{y}$, ciertamente, responderá preguntas que nos acercarán a la historia evolutiva de nuestra especie, pero sobre todo, será, como debe ser cualquier área productiva de la Ciencia, una fuente de nuevas preguntas que ahora mismo no podemos concebir.

\section{REFERENCIAS}

Boomsma, D., A. Busjahn, y Peltonen, L. (2002): «Classical twin studies and beyond», Nature Reviews Genetics, 3(11), pp. 872-82.

Bouchard, T. J., J. R. y McGue, M. (2003): «Genetic and environmental influences on human psychological differences», J. Neurobiol., 54(1), pp. 4-45.

Bouchard, T. J. (2004): «Genetic Influence on Human Psychological Traits», Curr Dir. Psich. Sci., 13, pp. 148-151.

CAMERER, C. F., (2003): Behavioral Game Theory: Experiments in Strategic Interaction, The Roundtable Series in Behavioral Economics, Princeton, Princeton University Press.

CAmerer, C. F. y Fehr, E. (2003): Measuring Social Norms and Preferences using Experimental Games: A Guide for Social Scientists, Zurich, Institute for Empirical Research in Economics.

- (2006): «When does «economic man» dominate social behavior?», Science, 311(5757), pp. 47-52.

CARdon, L. R. y Bell, J. I. (2001): «Association study designs for complex diseases», Nature Reviews Genetics, 2, pp. 91-99. 
DARWIN, C., (1959): On the origin of species by means of natural selection, London, John Murray.

EBSTEIN, R. P., (2006): «The molecular genètic architecture of human personality: beyond self-report questionnaires», Mol. Psychiatry, 11(5), pp. 427-45.

EICHLER, E. E., (2006): «Widening the spectrum of human genètic variation», Nat Genet, $38(1)$, pp. 9-11.

FEHR, E. y CAMERER, C. F. (2007): «Social neuroeconomics: the neural circuitry of social preferences», Trends. Cogn. Sci., 11(10), pp. 419-27.

GREEN et al. (2010): «A Draft Sequence of the Neanderthal Genome», Science, 328, pp. 710-22.

HАммоск, E. A., et al. (2005): «Association of vasopressin 1a receptor levels with a regulatory microsatellite and behavior», Genes Brain Behav., 4(5), pp. 289-301.

HAMmock, E. A. and Young, L. J. (2005a): «Microsatellite instability generates diversity in brain and sociobehavioral traits», Science, 308(5728), pp. 1630-4.

- (2005b): «Oxytocin, vasopressin and pair bonding: implications for autism», Philos. Trans. R. Soc. Lond. B. Biol. Sci., 361(1476), pp. 2187-98.

HARRIS, T. B., et al. (2007): «Age, Gene/Environment Susceptibility-Reykjavik Study: multidisciplinary applied phenomics», Am. J. Epidemiol., 165(9), pp. 1076-87.

IOANNIDIS, J. P., et al. (2001): «Replication validity of genètic association studies», Nat. Genet., 29(3), pp. 306-9.

IOANNIDIS, J. P., (2007): «Non-replication and inconsistency in the genome-wide association setting», Hum Hered, 64(4) pp. 203-13.

Jensen, K., J. CAll, y Tomasello, M. (2007a): «Chimpanzees are rational maximizers in an ultimatum game», Science, 318(5847), pp. 107-9.

- (2007b): «Chimpanzees are vengeful but not spiteful», Proc. Natl. Acad. Sci. U. S. A., 104(32): 13046-50.

Jobling, M. A., M. E. Hurles, y Tyler-Smith, C. (2004): «Human evolutionary Genetics. Origins, peoples and Disease», New York, Garland Science.

KNAFO, A., et al. (2008) «Individual differences in allocation of funds in the dictator game associated with length of the arginine vasopressin 1a receptor RS3 promoter region and correlation between RS3 length and hippocampal mRNA», Genes. Brain. Behav., 7(3), pp. 266-75.

Kosfeld, M., et al. (2005): «Oxytocin increases trust in humans», Nature, 435(7042), pp. 673-6.

LiM, M. M., et al. (2004): «Enhanced partner preference in a promiscuous species by manipulating the expression of a single gene», Nature, 429(6993), pp. 754-7.

MANOLIO, T. A. et al. (2009): «Finding the missing heritability of complex diseases», $\mathrm{Na}$ ture, 461, pp. 747-53.

Martin, N., D. Boomsma, y Machin, G. (1997): «A twin-pronged attack on complex traits», Nat Genet, 17(4), pp. 387-92.

MiKKELSEN, T. et al. (2005): «Initial sequence of the chimpanzee genome and comparison with the human genome», Nature, 437(7055), pp. 69-87.

PenNisi, E., (2007) «Breakthrough of the year. Human genètic variation , Science, 318(5858), pp. 1842-3.

PERRY, G.H., et al. (2006): «Hotspots for copy number variation in chimpanzees and humans», Proc. Natl. Acad. Sci. U. S. A., 103(21), pp. 8006-11.

aan het Rot, M., et al. (2006): «Social behaviour and mood in everyday life: the effects of tryptophan in quarrelsome individuals», J. Psychiatry. Neurosci., 31(4), 253-62. 
Reimers-KipPInG, S., W. Hevers, W., S. PÄÄBo, y EnARD, W. (2010): «Humanized Foxp2 specifically affects cortico-basal ganglia circuits», Neuroscience Nov 24. [Epub ahead of print]

SCHERER, S. W., et al. (2007): «Challenges and standards in integrating surveys of structural variation», Nat Genet, 39(7 Suppl), S7-15.

Sudmant, P. et al. (2010): «Diversity of Human Copy Number Variation and Multicopy Genes», Science, 330, pp. 641-646.

The 1000 Genomes Project Consortium (2010): «A map of human genome variation from population-scale sequencing», Nature, 467, pp. 1061-1073.

WAllace, B., et al. (2007): «Heritability of ultimatum game responder behavior», Proc. Natl. Acad. Sci. U. S. A., 104(40), pp. 15631-4.

WTCCC. Welcome Trust Case-Control Consortium (2007): «Genome-wide association study of 14,000 cases of seven common diseases and 3,000 shared controls», Nature, 447(7145), pp. 661-78.

YANG, J. et al. (2010): «Common SNPs explain a large proportion of the heritability for human height», Nat Genet. 42(7), pp. 565-9. Epub 2010 Jun 20.

YIRMIYA, N., et al. (2006): «Association between the arginine vasopressin 1a receptor (AVPR1a) gene and autism in a family-based study: mediation by socialization skills», Mol. Psychiatry, 11(5), 488-94.

YounG, L. J. y HАMмOск, E. A. (2007): «On switches and knobs, microsatellites and monogamy», Trends. Genet., 23(5), pp. 209-12. 